\title{
Publisher Correction: Evolution of human malaria
}

Jane M. Carlton

Correction to: Nature Microbiology https://doi.org/10.1038/s41564-018-0170-2, published online 24 May 2018.

In the version of this News \& Views originally published, the caption of Fig. 1 failed to acknowledge that the figure was adapted from Fig. 1 of E. J. Scully, U. Kanjee \& M. T. Duraisingh Curr. Opin. Microbiol. 40, 21-31; 2017. This omission failed to recognize the scholarly work of Erik J. Scully, Usheer Kanjee and Manoj T. Duraisingh in generating the original version of the figure. Figure 1 has now been replaced in the News \& Views with a new figure and caption (see below) describing the status of genome sequencing for primate-infecting species in the Plasmodium genus, and the paper by Scully et al. has been cited in the caption and added to the reference list at number 12 . The publisher and editors apologize to the authors of the original figure, the author of the News \& Views, and our readers for this mistake.

\begin{tabular}{|c|c|c|c|}
\hline & & Species & Year genome sequenced \\
\hline \multirow{15}{*}{ 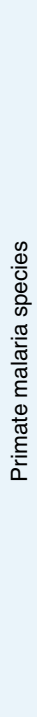 } & \multirow{8}{*}{$\begin{array}{l}\frac{0}{0} \\
\frac{\pi}{0} \\
\frac{\pi}{\pi} \\
\frac{\pi}{\pi} \\
\frac{\pi}{\pi} \\
0 \\
\frac{\pi}{\pi} \\
\frac{\hbar}{\pi}\end{array}$} & P. vivax & 2008 \\
\hline & & P. cynomolgi & 2012 \\
\hline & & P. coatneyi & 2016 \\
\hline & & P. knowlesi & 2008 \\
\hline & & P. gonderi & 2017 \\
\hline & & P. brasilianum & 2017 \\
\hline & & P. malariae & 2017 \\
\hline & & P. ovale & 2017 \\
\hline & \multirow{7}{*}{$\begin{array}{l}\frac{\pi}{0} \\
\frac{\pi}{0} \\
-\frac{\pi}{2} \\
\frac{\pi}{\sigma} \\
\stackrel{\pi}{0}\end{array}$} & P. adleri & 2018 (Otto et al.) \\
\hline & & P. gaboni & 2016; 2018 (Otto et al.) \\
\hline & & P. blacklocki & 2018 (Otto et al.) \\
\hline & & P. billcollinsi & 2018 (Otto et al.) \\
\hline & & P. reichenowi & 2007; 2018 (Otto et al.) \\
\hline & & P. praefalciparum & 2018 (Otto et al.) \\
\hline & & P. falciparum & 2002 \\
\hline
\end{tabular}

Fig. 1 | Primate malaria species with sequenced genomes. Plasmodium parasites infect a number of hosts in different regions of the world ${ }^{12}$. Indicated are the primate-infecting species for which genome sequences are available and the date when the first genome sequence for each of those species was published. 